\title{
Validity of Dynamic Prediction Model for Oxygen Uptake during Supra Maximal Intermittent Load Exercise
}

\author{
Shinji Takahashi", Tomonori Chiba**, Hiroaki Ishii ${ }^{* * *}$ and Takahiko Nishijima* \\ * Department of Health and Sport Sciences, Graduate School of Comprehensive Human Sciences, University of Tsukuba \\ 1-1-1 Tennodai, Tsukuba, Ibaraki 305-8574 Japan \\ shinji@stat.taiiku.tsukuba.ac.jp \\ ${ }^{* *}$ Faculty of Liberal Arts, Tohoku Gakuin University \\ 2-1-1 Tenjinzawa,Izumi-ku,Sendai 981-3193 Japan \\ ${ }^{* * *}$ Graduate School of human informatics, Tohoku Gakuin University \\ 2-1-1 Tenjinzawa,Izumi-ku,Sendai 981-3193 Japan \\ [Received August 19, 2004 ; Accepted January 21, 2005]
}

The purpose of this study was to determine the validity of a dynamic prediction (DP) model that predicts oxygen uptake $\left(\mathrm{V}_{2}\right)$ during supra maximal intermittent (SMI) exercise based on non-linearity of $\dot{\mathrm{V}} \mathrm{O}_{2}$ dynamics in comparing a heart rate (HR) model. Five male participants $(20 \pm 1 \mathrm{yrs})$ performed incremental exercise test used by cycle ergometer for the aim of developing individualized $\mathrm{HR}-\dot{\mathrm{V}} \mathrm{O}_{2}$ and workload- $\dot{\mathrm{V}} \mathrm{O}_{2}$ regression equations. The DP model was defined as a first order system to workload- $\dot{\mathrm{V}} \mathrm{O}_{2}$ relationship. Participants then completed SMI test corresponding at $140 \% \mathrm{VO}_{2}$ max while $\mathrm{HR}$ and $\dot{\mathrm{V}} \mathrm{O}_{2}$ data were collected continuously for $20 \mathrm{~min}$. The HR model predicted $\dot{\mathrm{V}} \mathrm{O}_{2}$ during SMI test used by HR, while the DP model also predicted $\dot{\mathrm{V}} \mathrm{O}_{2}$ from workload. Predicted values $\left(\dot{\mathrm{V}} \mathrm{O}_{2}\right)$ were compared with measured values $\left(\dot{\mathrm{V}} \mathrm{O}_{2}\right)$ obtained via a metabolic measurement system. The DP model showed a significantly higher relationship with measured $\dot{V}_{2} O_{2}\left(R^{2}=0.95, S E E=149 \mathrm{ml} / \mathrm{min}\right)$ in comparison with the HR model $\left(R^{2}=0.83, S E E=275 \mathrm{ml} / \mathrm{min}\right)$. The $\mathrm{HR}$ model showed significant systematic error $(r=0.41, P<.05)$, whereas the DP model did not $(r=0.06, P>$ $.05)$. For comparison of prediction errors of both models, the error of the DP model $(-1.3 \pm 8.8$ \%) was significantly smaller than the HR model (-8.0 $\pm 16.5 \%)$. The DP model also accurately estimated total energy expenditure. Therefore, the DP model is an accurate predictor of $\dot{\mathrm{V}} \mathrm{O}_{2}$ during supra maximal intermittent exercise.

Keywords: exercise intensity, heart rate, validity, accuracy

[International Journal of Sport and Health Science Vol.3, 68-74, 2005]

\section{Introduction}

In exercise training, intensity has been expressed in oxygen uptake $\left(\dot{\mathrm{V}}_{2}\right)$, relative value to maximum oxygen uptake $\left(\% \dot{\mathrm{V}} \mathrm{O}_{2} \mathrm{max}\right)$ and metabolic equivalents (METs) (American College of Sports Medicine: ACSM, 2000). There are many studies which have reported scientific evidence that the improvement of exercise performance depends on intensity (Busso, et al., 1990; Morton, et al., 1990; Pate \& Branch, 1992; ACSM, 2000). Therefore, it is necessary to monitor intensity in order to verify how effectively training is being carried out.
As a method for monitoring intensity, heart rate (HR) monitoring is widely used to predict $\dot{\mathrm{V}}_{2}$ during exercise (Morton, et al., 1990; O'Toole, et al., 1998; ACSM, 2000; Strath, et al., 2002). In the HR monitoring method, a $\dot{\mathrm{V}} \mathrm{O}_{2}$ prediction equation (HR model) is individually developed by linear regression analysis, setting HR during incremental load exercise as the independent variable and $\dot{\mathrm{V}}_{2}$ as the dependent variable. The procedure for preparing the HR model is a relatively easy and useful method for monitoring exercises ranging from low to high intensity. There are, however, some problems.

In the HR model, it is presupposed that the 
relationship between $\mathrm{HR}$ and $\dot{\mathrm{V}} \mathrm{O}_{2}$ during exercises is always linear. Nevertheless, since the linear relationship between $\mathrm{HR}$ and $\dot{\mathrm{V}} \mathrm{O}_{2}$ cannot be established during intermittent exercises that accompany sudden load changes and during exercises exceeding the $\dot{\mathrm{V}} \mathrm{O}_{2}$ max intensity (supra maximal intensity) (Achten, 2003), the HR model is markedly deteriorated in prediction accuracy during supra-maximum intermittent exercises. Deterioration of prediction accuracy might be caused by difference between $\dot{\mathrm{V}} \mathrm{O}_{2}$ dynamics and HR dynamics to the workload (Bearden \& Moffatt, 2001; Hughson, 2003). Both $\mathrm{HR}$ and $\dot{\mathrm{V}} \mathrm{O}_{2}$ dynamics during constant load exercises have been described by the exponential function model (Bearden \& Moffatt, 2001). It has been reported that the time constant estimated from the model is a parameter which presents the response speed to the workload and that the time constant between HR and $\dot{\mathrm{V}} \mathrm{O}_{2}$ dynamics is significantly different (Bearden \& Moffatt, 2001; Hughson, 2003).

Recently, many studies have adopted $\dot{\mathrm{V}} \mathrm{O}_{2}$ dynamics modeling, and its characteristics to the workload have been explained (Pool, et al., 1994; Morton \& Gregory, 1987; Miyamoto \& Niizeki, 1990; Hughson, et al., 1991; Swanson \& Hughson, 1988; Bell, et al., 1999; Cabrera, et al., 1999; Bahr, et al., 1992, Perrey, et al., 2002). Because the dose-response relationship between workload and $\dot{\mathrm{V}} \mathrm{O}_{2}$ dynamics is better defined, in the prediction of intensity under the conditions in which the workload (watt and running velocity) is easily obtained, such as with a bicycle ergometer or tread ergometer, it is preferable to get $\dot{\mathrm{V}} \mathrm{O}_{2}$ dynamics directly as the prediction method. The present study examined the validity of a $\dot{\mathrm{V}} \mathrm{O}_{2}$ dynamic prediction (DP) model based on $\dot{\mathrm{V}}_{2}$ dynamics characteristics in supra-maximum intermittent exercises by comparing it with the HR model.

\section{Methods}

\subsection{Subjects}

Five healthy males participated in this study. Their mean \pm SD of age, height, and weight were $20.0 \pm 1.0$ years, $176.6 \pm 5.4 \mathrm{~cm}$, and $73.1 \pm 5.5 \mathrm{~kg}$, respectively. After a detailed explanation of the study, informed consent was obtained.

\subsection{Workload test}

All tests were carried out in a laboratory controlled at a room temperature of $25^{\circ} \mathrm{C}$ and humidity of $50 \%$. Using an electrically braked cycle ergometer (aerobike 75XLII, Combi Co., Tokyo, Japan), for all tests, the subjects conducted a 3 min warm-up (0 $\mathrm{W})$ after a $5 \mathrm{~min}$ rest. The pedal frequency was held constant at $60 \mathrm{rpm}$ during all tests. In the multi-stage incremental load test, after a warm-up, the workload was increased by $30 \mathrm{~W} / 3 \mathrm{~min}$ after warming up and they performed to exhaustion. In the supra-maximum intermittent (SMI) test, one set consisted of a low load $\left(60 \mathrm{~W}, 30.3 \pm 1.8 \% \dot{\mathrm{V}} \mathrm{O}_{2}\right.$ max: Base) for the starting $3 \mathrm{~min}$, and a heavy intensity load (Trial) corresponding to $140 \% \dot{\mathrm{VO}}_{2}$ max for the subsequent $1 \mathrm{~min}$, and the subjects had to repeat 5 sets. All the subjects performed the multi-stage incremental load test on the first day and the SMI test on another day. Multi-stage incremental load test data were used for modeling of the HR model and the DP model, and SMI test data were set as the validity criterion.

$\dot{\mathrm{V}} \mathrm{O}_{2}$ and HR in all tests were measured from rest to the end of exercise by a breath-by-breath method using AE-300s (Minato Medical Science Co., Osaka, Japan). The measured values of $\dot{\mathrm{VO}}_{2}$ and HR were averaged for $60 \mathrm{sec}$ intervals both in the multi-stage incremental load test and the SMI test.

$\dot{\mathrm{V}} \mathrm{O}_{2}$ max was determined from multi-stage incremental load test data. $\dot{\mathrm{V}} \mathrm{O}_{2} \mathrm{max}$ was decided with leveling-off when an increase of $\dot{\mathrm{V}}_{2}$ becomes below $150 \mathrm{ml} / \mathrm{min}$ of the previous load, as the first

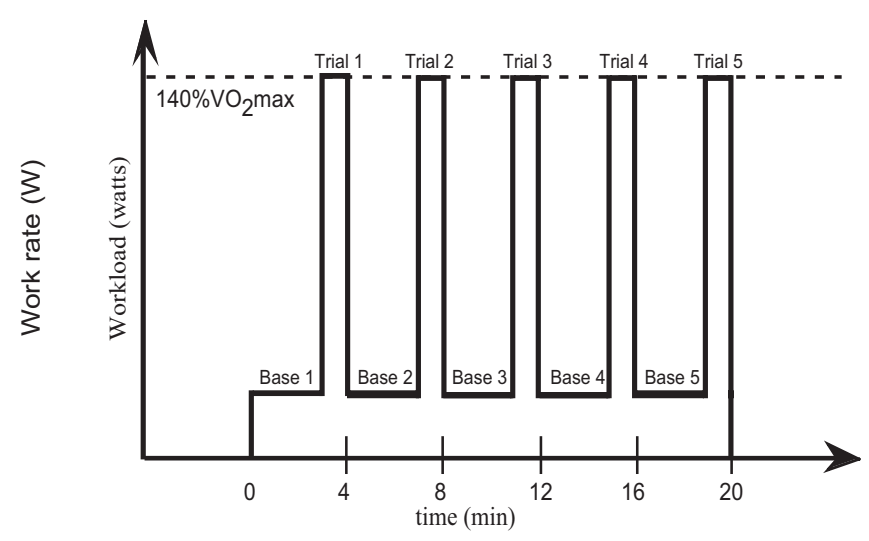

Figure 1 Super maximal intermittent (SMI) test protocol. 
criterion (Taylor, et al., 1955). When leveling-off was not observed, it was decided at highest $\dot{\mathrm{VO}}_{2}$ at the time of appearance of $\mathrm{R}$ of above 1.15 (Tanaka, et al., 1986).

\subsection{DP model}

Feedback control works in many physiological responses. Feedback control is considered to work on the energy supply system during exercise, too. That is, deficiency of energy at an early period of exercise and recovery period increases or decreases energy supplement. With the decrease in the difference between supply and demand, the increase or decrease of the energy supply system becomes moderate and, then, reaches a steady state. The $\dot{\mathrm{V}} \mathrm{O}_{2}$ steady state is proportional to the workload (Medb $\varnothing$, et al., 1988). This relationship explains why the main dynamics of $\dot{\mathrm{VO}}_{2}$ are regarded as the first order system to the workload or energy demand (Pool, et al., 1996; Morton \& Gregory, 1987; Miyamoto \& Niizeki, 1990; Hughson, et al., 1987). Accordingly, the DP model was described as the following:

$\dot{\mathrm{V}}_{2}(\mathrm{t})=\dot{\mathrm{V}} \mathrm{O}_{2}(\mathrm{t}-\mathrm{dt})+\Delta \dot{\mathrm{V}} \mathrm{O}_{2} \cdot \mathrm{dt}$

$\Delta \dot{\mathrm{V}}_{2}=\dot{\mathrm{V}} \mathrm{O}_{2}$ discrepancy $/ \tau$

$\dot{\mathrm{V}} \mathrm{O}_{2}$ discrepancy $=\mathrm{MIN}\left(\left(\right.\right.$ Energy $\left.-\dot{\mathrm{V}} \mathrm{O}_{2}\right),\left(\dot{\mathrm{V}} \mathrm{O}_{2} \mathrm{max}-\right.$ $\left.\dot{\mathrm{V}} \mathrm{O}_{2}\right)$ )

energy demand $=a \cdot$ Work rate $+b$

where, $\mathrm{a}=$ regression coefficient; $\mathrm{b}=$ regression constant, $\tau=$ time constant $30 \mathrm{sec} ; \mathrm{MIN}=$ minimal function. Regression analysis was used for the estimation of regression coefficient and regression constant, and the time constant $\tau$ was determined from previous studies (Hughson, et al., 1991; Swanson \& Hughson, 1988; Bell, et al., 1999; Cabrera, et al., 1999). The MIN function selects a minimal argument out of the arguments in parentheses. Even if energy demand is more than $\dot{\mathrm{V}} \mathrm{O}_{2}$ max, $\dot{\mathrm{V}} \mathrm{O}_{2}$ does not exceed $\dot{\mathrm{V}} \mathrm{O}_{2}$ max. Energy demand was determined by the linear regression expression with the last 1 min $\dot{\mathrm{V}}_{2}$ being the dependent variable, and the workload being the independent variable at each load stage in the multi-stage incremental load test. The hypothesis that $\dot{\mathrm{V}} \mathrm{O}_{2}$ dynamics reaches a steady state in $3 \mathrm{~min}$ considers the characteristic of reaching a steady state in the time passage 4 times the time constant
(30 sec) when regarding $\dot{\mathrm{VO}}_{2}$ dynamics as the first order system to the workload (Furuta, et al., 2001). The criterion to accept a regression line was the determination coefficient of more than $\mathrm{R}^{2}=0.98$.

In the post-exercise recovery period more than the intensity of $70 \% \dot{\mathrm{V}} \mathrm{O}_{2}$ max, effects of post-exercise excess oxygen consumption (EPOC) were observed (Schneider, et al., 1968; Bahr, et al., 1992), and the time constant of $\dot{\mathrm{V}}{ }_{2}$ dynamics changes (Perrey, et al., 2002). Perrey, et al. (2002) have reported that by the effect of EPOC, the time constant $\tau$ becomes slower to approximately $95 \mathrm{sec}$. Therefore, EPOC effects in the DP model were described using the IF function as follows:

$\Delta \dot{\mathrm{VO}}_{2}=\mathrm{IF}((\mathrm{SMTH} 1$ (work rate, $60 \mathrm{sec}) \geqq$ work rate at $70 \% \dot{\mathrm{V}} \mathrm{O}_{2}$ max $)$ and $>\dot{\mathrm{V}} \mathrm{O}_{2}$ discrepancy $<0$ )

THEN ( $\dot{\mathrm{V} O} 2$ discrepancy $/ 95 \mathrm{sec})$

ELSE ( $\dot{\mathrm{V}}_{2}$ discrepancy/30 sec)

where, SMTH1 is a smoothing function. When the workload $60 \mathrm{sec}$ before had an average of more than the workload in the $70 \% \dot{\mathrm{V}}{ }_{2}$ max level and the $\dot{\mathrm{V}}{ }_{2}$ discrepancy was negative, we set the time constant of $\dot{\mathrm{V}} \mathrm{O}_{2}$ dynamics to $95 \mathrm{sec}$ and to $30 \mathrm{sec}$ for other conditions.

The DP model was modeled using the software STELLA 5.1J (High Performance, New Hampshire, USA) specially designed for System Dynamics that is a technique of dynamic simulation. The fourth-order Runge-Kutta method was used to compute the model, and the delta time of computation was $20 \mathrm{sec}$.

\subsection{HR model}

The HR model was modeled by applying a method (flex heart rate: Flex HR) established by Livingstone, et al. (1990). Flex HR is a method that solves underestimation of $\dot{\mathrm{V}} \mathrm{O}_{2}$ during low intensity exercises. This solution method against $\dot{\mathrm{V}}_{2}$ underestimation substitutes the average of highest HR during rest and lowest HR during the multi-stage incremental load test (Flex HR point) when an HR lower than the HR during rest was obtained in the multi-stage incremental load test. The HR model was determined by the regression line with the HR obtained from the incremental load test being the independent variable and $\dot{\mathrm{V}} \mathrm{O}_{2}$ the dependent variable. As the criterion to accept the individual HR 
Table 1 Comparison of relative error scores (RES) between HR and DP models.

\begin{tabular}{|c|c|c|c|c|c|c|c|c|c|c|c|c|c|}
\hline \multirow[t]{2}{*}{ Subjects } & \multirow{2}{*}{$\begin{array}{l}\text { Age } \\
\text { (yrs) }\end{array}$} & \multirow{2}{*}{$\begin{array}{r}\text { Height } \\
(\mathrm{cm})\end{array}$} & Weight & \multicolumn{2}{|c|}{$\mathrm{VO}_{2} \max \mathrm{HRmax}$} & \multirow{2}{*}{$\frac{\text { Watt }}{\text { (watt) }}$} & \multicolumn{3}{|c|}{ energy demand } & \multicolumn{3}{|c|}{ HR model } & \multirow{2}{*}{$\begin{array}{r}\begin{array}{r}\text { Workload } \\
\text { at SMI test }\end{array} \\
\text { (watt) }\end{array}$} \\
\hline & & & $(\mathrm{kg})$ & $(\mathrm{ml} / \mathrm{min})$ & (bpm) & & slope: & stant & $\mathrm{R}^{2}$ & slope & onstant & $\mathrm{R}^{2}$ & \\
\hline YS & 19 & 176 & 72.6 & 2883 & 189 & 240 & 10.6 & 593 & 0.99 & 21.7 & -946 & 1.00 & 340 \\
\hline TT & 19 & 173 & 66.4 & 3101 & 180 & 270 & 10.2 & 703 & 1.00 & 22.7 & -1077 & 1.00 & 380 \\
\hline KT & 21 & 186 & 77.3 & 3359 & 176 & 270 & 10.9 & 673 & 0.99 & 23.7 & -1084 & 0.99 & 380 \\
\hline $\mathrm{SN}$ & 20 & 174 & 69.5 & 3064 & 186 & 240 & 10.7 & 667 & 0.99 & 22.3 & -1342 & 0.99 & 340 \\
\hline $\mathrm{KO}$ & 21 & 174 & 79.7 & 3093 & 184 & 270 & 9.8 & 754 & 0.99 & 17.8 & -756 & 0.98 & 380 \\
\hline mean & 20 & 177 & 73.1 & 3100 & 183 & 258 & 10.4 & 678 & & 21.6 & -1041 & & 364 \\
\hline SD & 1 & 5 & 5.5 & 170 & 5 & 16 & 0.4 & 59 & & 2.3 & 214 & & 22 \\
\hline
\end{tabular}

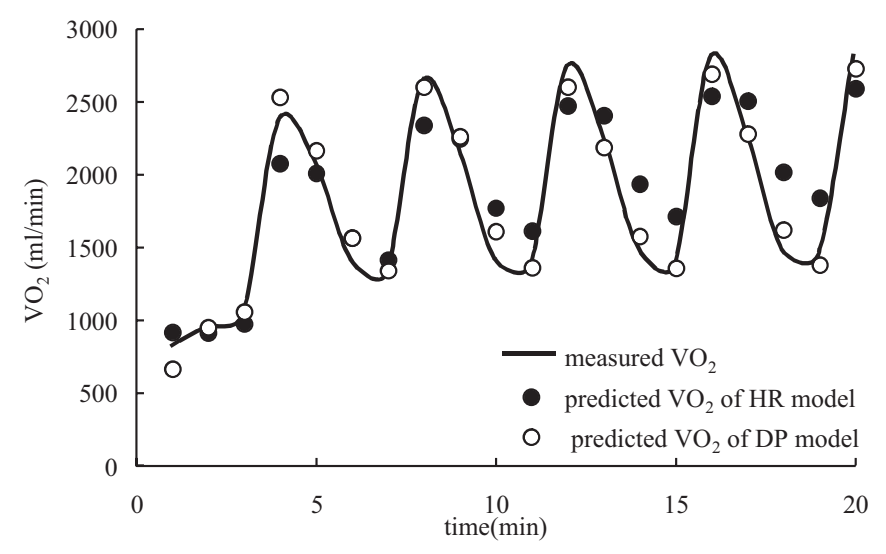

Figure 2 Fitting of predictions to measurement during SMI test at $140 \% \dot{\mathrm{V}} \mathrm{O}_{2}$ max. Solid line showed measured $\dot{\mathrm{VO}}_{2}$, • was symbol of predicted values by HR model, $\mathrm{O}$ was symbol of predicted values by DP model. Theses data were average of all subjects.

models, the determination coefficient of more than $\mathrm{R}^{2}$ $=0.98$ was used.

\subsection{Statistical analysis}

The validity of the HR model and the DP model was examined from determination coefficient to validity criterion (measured $\dot{\mathrm{V}}_{2}$ obtained from the SMI test), degree of agreement of the models with validity criterion and existence of systematic error in the Bland and Altman plot (1986), comparison of total energy expenditure (TEE), and relative error score (RES) in the total SMI test. The TEE and RES were calculated in the following expression: TEE $(\mathrm{kcal})=$ sum of $\dot{\mathrm{V}} \mathrm{O}_{2} / 1000(\mathrm{~L}) \times 5.0\left(\mathrm{kcal} / \mathrm{O}_{2} \mathrm{~L}\right)$ $\operatorname{RES}(\%)=($ prediction - criterion $) /$ criterion $\times 100$

For TEE comparison, when a significant main effect could be obtained using ANOVA with repeated measurements (3 levels: validity criterion, the HR model, and the DP model), a multiple comparison test by the Bonfferroni method was performed. For
Table 2 Oxygen uptake (mean \pm SD) and determination coefficients of HR and DP models to measured $\mathrm{VO}_{2}$ during SMI test.

\begin{tabular}{lccc}
\hline Method & $\mathrm{VO}_{2}(\mathrm{ml} / \mathrm{min})$ & $\mathrm{R}^{2}$ & $: \mathrm{EE}(\mathrm{ml} / \mathrm{mir}$ \\
\hline Measurem & $1807 \pm 658$ & - & - \\
HR model & $1892 \pm 547$ & $0.83^{*}$ & 275 \\
DP model & $1826 \pm 650$ & $0.95 *$ & 149 \\
\hline & & & $*: P<.05$
\end{tabular}

RES comparison, a paired $t$ test was used. The overall significance level was set at $\alpha=0$. All statistical analyses were completed using SPSS $12.0 \mathrm{~J}$ for Windows.

\section{Results}

All measured values are shown in the mean \pm SD. Table 1 shows the measuring items, energy demand and the HR model of each subject in the multi-stage incremental load test. $\dot{\mathrm{V}} \mathrm{O}_{2} \max$ was $3100 \pm 170$ $\mathrm{ml} / \mathrm{min}$, and the HR maximum value (HRmax) was $183 \pm 5 \mathrm{bpm}$. The regression coefficient of energy demand in the 5 subjects was $10.4 \pm 0.4$, and the regression constant was $364 \pm 41$. The regression coefficient and constant of the HR model were 21.6 \pm 2.3 and $-1041 \pm 214$. Both energy demand and the HR model showed a determination coefficient $\left(\mathrm{R}^{2} \geqq\right.$ 0.98 ) of more than the accepted criterion.

Figure 2 shows the goodness of fit of the measured $\dot{\mathrm{V}} \mathrm{O}_{2}$, the predicted $\dot{\mathrm{V}} \mathrm{O}_{2}$ of the HR model and the DP model in the SMI test. Table 2 shows the measured $\dot{\mathrm{V}} \mathrm{O}_{2}$, the predicted $\dot{\mathrm{V}} \mathrm{O}_{2}$ by the HR model, the predicted $\dot{\mathrm{V}} \mathrm{O}_{2}$ by the DP model, and the determination coefficient of the HR model and the DP model to the measured $\dot{\mathrm{V}} \mathrm{O}_{2}$ during the SMI test. The measured $\dot{\mathrm{V}} \mathrm{O}_{2}$ was $1807 \pm 658 \mathrm{ml} / \mathrm{min}$, the prediction value by the HR model was $1892 \pm 547 \mathrm{ml} / \mathrm{min}$, and the prediction value of the DP model was $1826 \pm$ 

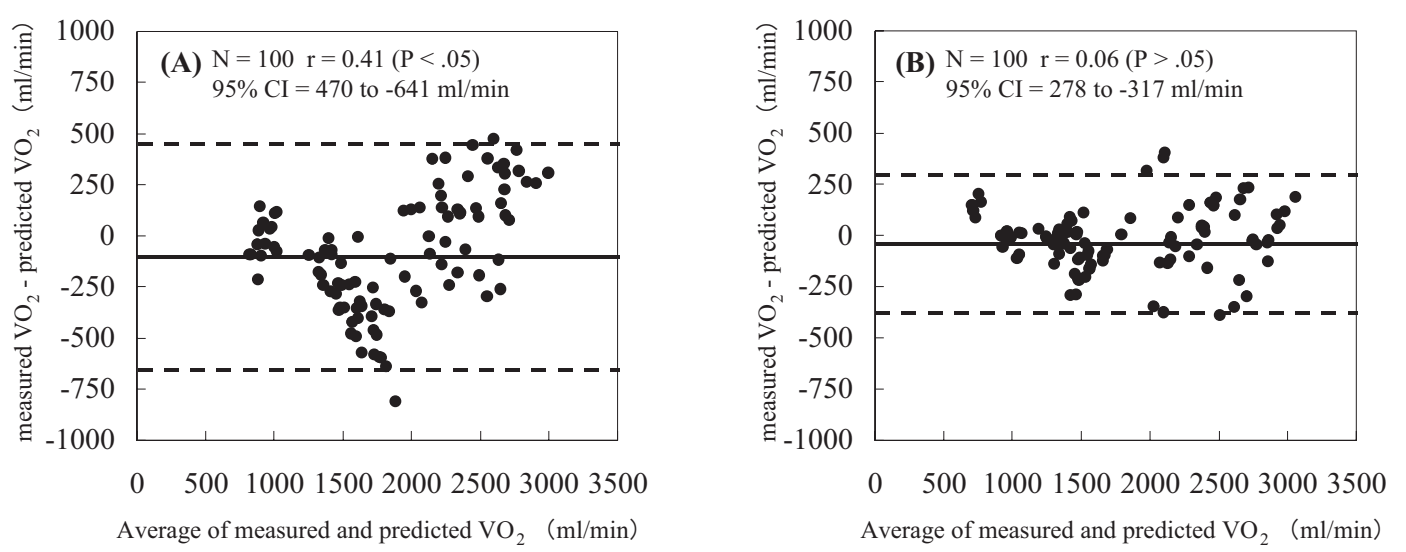

Figure 3 Bland and Altman plots depiciting error scores minute-by-minute prediction for (A) HR model, (B) DP model during SMI test. The solid line represents the mean error, and the dash line represents the $95 \%$ confidence interval.

Table 3 Comparison of total energy expenditure predicted by HR and DP models.

\begin{tabular}{lc}
\hline Methods & TEE $(\mathrm{kcal})$ \\
\hline Measurement & $180.7 \pm 14.2$ \\
HR model & $189.2 \pm 15.0$ \\
DP model & $182.6 \pm 14.4$ \\
\hline
\end{tabular}

The main effect was not significant for ANOVA with repeated measurements.

$650 \mathrm{ml} / \mathrm{min}$. The determination coefficient of the HR model was $\mathrm{R}^{2}=0.83$, and that of the DP model was $\mathrm{R}^{2}=0.95$.

Figure 3 shows the Bland and Altman plot of the HR model and the DP model in the SMI test. The mean error of the HR model was $-86 \mathrm{ml} / \mathrm{min}$ and the $95 \%$ confidence interval (CI) ranged from 470 to $-641 \mathrm{ml} / \mathrm{min}$. The mean error of the DP model was $-19 \mathrm{ml} / \mathrm{min}$ and $95 \% \mathrm{CI}$ from 278 to -317 . Also, in the Bland and Altman plot, a significant correlation coefficient $(\mathrm{r}=0.41, P<.05)$ was observed in the error of the HR model.

Table 3 shows the TEE measured in the total SMI test, the predicted TEE by the HR model, and the predicted TEE by the DP model. The measured TEE was $180.7 \pm 14.2 \mathrm{kcal}$, the predicted TEE by the HR model was $189.2 \pm 15.0 \mathrm{kcal}$, and predicted TEE by the DP model was $182.6 \pm 14.4 \mathrm{kcal}$. In ANOVA with repeated measurements, a significant main effect was not observed among 3 levels.

Table 4 shows the RES of the HR model and the DP model. The RES of the HR model was $-8.0 \pm$ $16.5 \%$ while that of the DP model was $-1.3 \pm 8.8 \%$.
Table 4 Comparison of relative error scores (RES) between HR and DP models.

\begin{tabular}{ll}
\hline Methods & RES $(\%)$ \\
\hline HR model & $-8.0 \pm 16.5^{*}$ \\
DP model & $-1.3 \pm 8.8$ \\
\hline & $*: P<.05$
\end{tabular}

The RES of the HR model showed a significantly low value in the paired $t$ test.

\section{Discussion}

The major finding of the present study was that the determination coefficient $\left(\mathrm{R}^{2}=0.95\right)$ to the measured $\dot{\mathrm{V}} \mathrm{O}_{2}$ of the DP model showed higher values than the HR model $\left(\mathrm{R}^{2}=0.83\right)$ during supra maximal intermittent exercises. In the Bland and Altman plot, $95 \% \mathrm{CI}$ of the DP model was in a narrower range than the HR model and there was no systematic error. Also, in RES comparison, the DP model had far fewer errors than the HR model. These results showed that the DP model that considers $\dot{\mathrm{V}}_{2}$ dynamic characteristics has higher prediction accuracy than the HR model that has been widely used. It can be decide that the DP model is a sufficiently valid method as a $\dot{\mathrm{V}}_{2}$ prediction method.

The HR model had a systematic error in the Bland and Altman plot $(\mathrm{r}=0.41, P<.05)$. When visually analyzing the plot, it is assumed that errors in the HR model consist of two components. We 
can consider that errors when $\dot{\mathrm{V}}_{2}$ is less than $1500 \mathrm{ml} / \mathrm{min}$ increase toward the negative direction with the increase of intensity and errors more than $1500 \mathrm{ml} / \mathrm{min}$ increase toward the positive direction with the increase of intensity (Figure 3). Achten (2003) has reported that in the phase of a sudden increase or decrease in the workload, because the HR dynamics becomes slower than the $\dot{\mathrm{V}} \mathrm{O}_{2}$ dynamics, the prediction accuracy of $\dot{\mathrm{V}} \mathrm{O}_{2}$ of the HR model drastically declines. In the HR model, $\dot{\mathrm{V}} \mathrm{O}_{2}$ is underestimated in the phase of a sudden increase of the load and overestimated in the phase of a decrease of the load. In the present study, since supra maximum intermittent exercises set as a valid criterion are exercises that repeat sudden load increase and decrease, two error components visually recognized in the Bland and Altman plot should be a clearly striking result that reflected HR model characteristics. Also, although the HR model showed lower prediction accuracy than the DP model in determination of the coefficient and RES comparison, TEE comparison was not significantly different from the measured TEE. This result might stem from a counterbalance of two error components by the summation of $\dot{\mathrm{V}}_{2}$.

The DP model examined in the present study had high validity in the supra maximum intermittent pedaling exercise. The DP model is modeled under several hypothetical conditions. Procedures necessary for modeling are collection of incremental load test data and determination of energy demand. Therefore, it should be similar in ease to the modeling of the HR model. Takahashi, et al. (2003) have reported that by modeling an expired gas dynamics model using System Dynamics similar to the DP model, the expired gas dynamics model had sufficient prediction accuracy in $\dot{\mathrm{V}}{ }_{2}$ prediction at the times of incremental load pedaling exercise and constant load pedaling exercise of sub-maximal intensity $\left(50-70 \% \dot{\mathrm{V}} \mathrm{O}_{2}\right.$ max $)$. Accordingly, the DP model is thought to be useful as a $\dot{\mathrm{V}} \mathrm{O}_{2}$ prediction method in both steady state and non-steady state. Nevertheless, the validity of the DP model reported in the previous and present studies is limited to pedaling exercises on bicycle ergometers. Pedaling exercise is an easy exercise form for measuring the workload (watt) that is an independent variable of the DP model, so the DP model cannot satisfy enough applicability. For future research, the applicability of the DP model should be verified as a method to measure running or physical activity in free-living activity (METs) by setting values measured by a pedometer or accelerometer as the independent variable.

In the present study, by the comparison with the HR model, the validity of the DP model in supra maximum intermittent exercise was examined. The DP model showed higher prediction accuracy than the HR model in the measured $\dot{\mathrm{V}} \mathrm{O}_{2}$, and the validity of the DP model was verified.

\section{Limitations}

In this study, to compare the HR model with the DP model, two models were modeled from the same test data, that is, multi-stage incremental load test data. The constructed DP model has the following limitations:

1) Effect of slow component: It is known that there are slow components in $\dot{\mathrm{V}} \mathrm{O}_{2}$ dynamics of high intensity exercises over the intensity of lactate threshold (LT) so that systematic errors are contained in the prediction value of the DP model in which the simple first order system to energy demand is presupposed. Since it is difficult to estimate parameters in slow components in the multi-stage incremental load test, future research should be focused on constant load testing of high intensity and to improve the accuracy of the DP model by adding slow component parameters.

2) Individual variation in time constant $\tau$ of $\dot{\mathrm{V}} \mathrm{O}_{2}$ dynamics: Because it was difficult to estimate the time constant $\tau$ when determining dynamic characteristics of $\dot{\mathrm{V}} \mathrm{O}_{2}$ dynamics from multi-stage incremental load test data, the present study set the time constant to 30 sec or $95 \mathrm{sec}$ in $70 \% \dot{\mathrm{V}} \mathrm{O}_{2}$ max intensity post-exercise for all the subjects. However, individual variation of approximately $\pm 20 \mathrm{sec}$ is known according to gender, age, muscular fiber composition and exercise habit in the time constant $\tau$ (Morton \& Gregory, 1987; Barstow, et al., 1996; Perrey, et al., 2002). For applying the DP model to females, children, middle-aged and elderly people, individual estimation should be prepared for the time constant $\tau$ of $\dot{\mathrm{V}} \mathrm{O}_{2}$ dynamics. 


\section{References}

Achten, J., and Jeukendrup, A.E. (2003) Heart rate monitoring: applications and limitations. Sports Med. 33:517-538.

American College of Sports Medicine (2000) ACSM'sGuidelines for Graded Exercise Testing and Prescription (6th ed.). Williams \& Wilkins, Philadelphia, 134-163.

Bahr, R., Gronnerod, O., and Sejersted, O.M. (1992) Effect of supramaximal exercises on excess postexercise $\mathrm{O} 2$ consumption. Med. Sci. Sports Exerc. 24: 66-71.

Barstow, T.J., Jones, A.M., Nguyen, P.H, and Casaburi, R. (1996) Influence of muscle fiber type and pedal frequency on oxygen uptake kinetics of heavy exercise. J. Appl. Physiol. 81: 1642-1650.

Bearden, S.E., and Moffatt, R.J. (2001) $\dot{\mathrm{VO}}_{2}$ and heart rate kinetics in cycling: transitions from an elevated baseline. J. Appl. Physiol. 90: 2081-2087.

Bell, C., Kowalchuk, J.M., Paterson, D.H., Scheuermann, B.W., and Cunningham, D.A. (1999) The effects of caffeine on the kinetics of $\mathrm{O} 2$ uptake, $\mathrm{CO} 2$ production and expiratory ventilation in humans during the on-transient of moderate and heavy intensity exercise. Exp. Physiol. 84: 761-774.

Bland, J.M., and Altman, D.G. (1986) Statistical methods for assessing agreement between two methods of clinical measurement. Lancet. 338: 1622-1623.

Busso, T., Hakkinen, K., Pakarinen, A., Carasso, C., Lacour, J.R., Komi, P.V., and Kauhanen, H. (1990) A systems model of training responses and its relationship to hormonal responses in elite weight-lifters. Eur. J. Appl. Physiol. Occup. Physiol. 61: 48-54.

Cabrera, M.E., Saidel, G.M., and Kalhan, S.C. (1999) Lactate metabolism during exercise: analysis by an integrative systems model. Am. J. Physiol. 277:1522-1536.

Furuta, K., Hatakeyama, S., and Nonaka, K. (2001) Modeling and Feedback Control. Tokyo Denki University Press. Tokyo. pp 117-120. (in Japanese)

Hughson, R.L. (2003) Regulation of Blood Flow at the Onset of Exercise by Feed Forward and Feedback Mechanisms. Can. J. Appl. Physiol. 28:774-787.

Hughson, R.L., Xing, H.C., Borkhoff, C., Butler, G.C. (1991) Kinetics of ventilation and gas exchange during supine and upright cycle exercise. Eur J Appl Physiol Occup Physiol. 63:300-307.

Livingstone, M.B., Prentice, A.M., Coward, W.A., Ceesay, S.M., Strain, J.J., McKenna, P.G., Nevin, G.B., Barker, M.E., Hickey, R.J. (1990) Simultaneous measurement of free-living energy expenditure by the doubly labeled water method and heart-rate monitoring. Am. J. Clin. Nutr. 52: 59-65.

Medbø, J.I., Mohn, A.C., Tabata, I., Bahr, R., Vaage, O., and Sejersted, O.M. (1988) Anaerobic capacity determined by maximal accumulated O2 deficit. J. Appl. Physiol. 64:50-60.

Miyamoto, Y., and Niizeki, K. (1992) Dynamics of ventilation, circulation, and gas exchange to incremental and decremental ramp exercise. J. Appl. Physiol. 72: 2244-2254.

Morton, R.H., and Gregory, C.G. (1987) A systems model approach to the ventilatiory anaerobic threshold. Eur. J. Appl. Physiol. Occup. Physiol. 56: 367-373.

Morton, R.H., Fitz-Clarke, J.R., and Banister, E.W. (1990) Modeling human performance in running. J. Appl. Physiol. 69: 1171-1177.

O'Toole, M.L., Douglas, P.S., and Hiller, W.D. (1998) Use of heart rate monitors by endurance athletes: lessons from triathletes. J. Sports Med. Phys. Fitness. 38:181-187.
Pate, R., and Branch, J.D. (1992) Training for endurance sports. Med. Sci. Sports Exec. 24: S340-343.

Perrey, S., Candau, R., Borrani, F., Millet, G.Y., and Rouillon J.D. (2002) Recovery kinetics of oxygen uptake following severe-intensity exercise in runners. J. Sports Med. Phys. Fitness 42: 381-388.

Poole, D.C., Barstow, T.J., Gaesser, G.A., Willis, W.T., and Whipp, B.J. (1994) VO2 slow component: physiological and functional significance. Med. Sci. Sports. Exerc. 26: 1354-1358.

Schneider. E.G., Robinson, S., and Newton, J.L. (1968) Oxygen debt in aerobic work. J. Appl. Physiol. 25: 58-62.

Strath, S.J., Bassett, D.R. Jr., Thompson, D.L., and Swartz, A.M. (2002) Validity of the simultaneous heart rate-motion sensor technique for measuring energy expenditure. Med. Sci. Sports Exerc. 34: 888-894.

Swanson, G.D., and Hughson, R.L. (1988) On the modeling and interpretation of oxygen uptake kinetics from ramp work rate tests. J. Appl. Physiol. 65: 2453-2458.

Takahashi, S., Nishijima, T., Chiba, T. and Ishii, H. (2003) Validity of expired gas simulation model during constant load exercise. IJSHS. 1: 119-128.

Tanaka, K., Watanabe, H., Konishi, Y., Mitsuzono, R., Sumida, S., Tanaka, S., Fukuda, T., and Nakadomo, F. (1986) Logtitudinal associations between anaerobic threshold and distance running performance. Eur. J. Appl. Physiol. Occup. Physiol. 55: 248-252.

Taylor, H.L., Busirk, E., and Henschel, A. (1955) Maximal oxygen uptake measure of cardio-respiratory performance. J. Appl. Physiol. 8: 73-80.

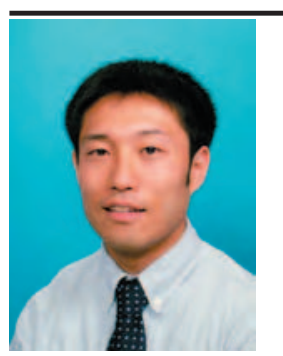

\section{Name: \\ Shinji Takahashi}

\section{Affiliation:}

Department of Health and Sport Sciences, Graduate School of Comprehensive Human Sciences, University of Tsukuba

\section{Address:}

1-1-1 Tennodai, Tsukuba, Ibaraki 305-8574 Japan

\section{Brief Biographical History:}

1999- Master's Program in Health and Physical Education, University of Tsukuba

2001- Doctoral Program in Health and Sport Science, University of Tsukuba

2004- Received Ph.D at University of Tsukuba.

2004- Researcher (COE), Graduate School of Comprehensive Human Sciences, University of Tsukuba

\section{Main Works:}

- System dynamics modeling of expired gas dynamics during incremental test. Japan J. Phys. Educ. Hlth. Sport Sci. 48: 169-180, 2003. (in Japanese with English abstract)

- Validity of expired gas simulation model during constant load exercise. IJSHS. 1: 119-128, 2003

\section{Membership in Learned Societies:}

- Japan Society of Physical Education, Health and Sport Science

- Japan Society of Physical Fitness and Sports Medicine

- American College of Sports Medicine

- The Japanese Chapter of the System Dynamics Society 